\title{
Democracia digital, participação e disseminação do conhecimento
}

\author{
Maria Cristina Piumbato Innocentini Hayashi \\ Camila Carneiro Dias Rigolin \\ Danilo Rothberg \\ Carlos Roberto Massao Hayashi
}

\section{SciELO Books / SciELO Livros / SciELO Libros}

HAYASHI, MCPI., et al. Democracia digital, participação e disseminação do conhecimento. In HAYASHI, MCPI., SOUSA, CM., and ROTHBERG, D., orgs. Apropriação social da ciência e da tecnologia: contribuições para uma agenda [online]. Campina Grande: EDUEPB, 2011. pp. 191-217. ISBN 978-85-7879-187-2. Available from SciELO Books <http://books.scielo.org>.

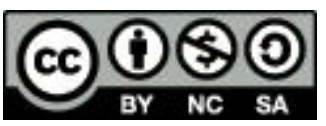

All the contents of this work, except where otherwise noted, is licensed under a Creative Commons Attribution-Non Commercial-ShareAlike 3.0 Unported.

Todo o conteúdo deste trabalho, exceto quando houver ressalva, é publicado sob a licença Creative Commons Atribuição Uso Não Comercial - Partilha nos Mesmos Termos 3.0 Não adaptada.

Todo el contenido de esta obra, excepto donde se indique lo contrario, está bajo licencia de la licencia Creative Commons Reconocimento-NoComercial-CompartirIgual 3.0 Unported. 


\title{
Democracia digital, participação e disseminação do conhecimento
}

\author{
Maria Cristina Piumbato Innocentini Hayashi \\ Camila Carneiro Dias Rigolin \\ Danilo Rothberg \\ Carlos Roberto Massao Hayashi
}

\section{Introdução}

Os últimos vinte anos foram marcados pela institucionalização da consulta da sociedade civil organizada nos processos de formulação de políticas públicas. A participação social tornou-se, a partir de então, um dos princípios organizativos mais aclamados por agências nacionais e internacionais, dos processos de formulação de políticas públicas e de deliberação democrática em escala local e nacional. Fomentar a participação dos diferentes atores sociais em sentido abrangente e criar uma rede que informe, elabore, implemente e avalie as decisões políticas tornou-se 
o paradigma de inúmeros projetos de desenvolvimento (auto) qualificados de inovadores e de políticas públicas locais consideradas progressistas.

Empiricamente, os anos 1990 corresponderam à institucionalização da consulta da população em geral, de associações, dos sindicatos, dos experts e de segmentos empresariais no processo de formulação de projetos de desenvolvimento e de políticas públicas. Originalmente identificada com correntes mais heterodoxas, a retórica da participação foi progressivamente incorporada por uma plêiade de atores (centros de pesquisa, ONGs, agências de financiamento internacional e órgãos governamentais) e, contemporaneamente, está presente nos discursos de atores e instituições tão heterogêneos quanto o Banco Mundial e o Fórum Social Mundial. Fomentar a participação dos diferentes atores tornou-se o paradigma de todo projeto de desenvolvimento e quaisquer políticas públicas consideradas progressistas (Milani, 2007). É evidente que daí decorrem questionamentos críticos acerca do significado e do fundamento da participação social nos diferentes contextos.

No âmbito da administração pública, por sua vez, a participação social é apresentada por um grupo de autores como resposta necessária aos impactos nocivos do Estado na construção de uma cidadania ativa; outros cientistas políticos e sociólogos vêm trabalhando com a hipótese do (re)surgimento da democracia participativa baseada em diferentes formas de delegação da representação política (AVRITZER, 2003; DAGNINO, 2002; LUCHMAN, 2002). Um terceiro grupo de autores associa a adoção de mecanismos participativos à crise do modelo burocrático de 
administração pública (BRESSER-PEREIRA; SPINK, 1998) e aos processos de reforma do Estado (especialmente na América Latina), em curso desde a década de 1990, que tendem a incluir, por exemplo, estratégias de descentralização, a adoção de mecanismos de responsabilização dos gestores (responsiveness e accountability), a gestão pública por resultados, o incremento do controle social, além de dispositivos de participação social que visam a chamar cidadãos e organizações cívicas para atuarem como atores políticos da gestão pública.

Em síntese, a participação social - também conhecida como dos cidadãos, popular, democrática, comunitária, entre os muitos termos atualmente utilizados para referir-se à prática de inclusão dos cidadãos e das organizações da sociedade civil no processo decisório de algumas políticas públicas - foi erigida em princípio político e administrativo, declarado e repetido em foros regionais e internacionais. Fazer participar os cidadãos e as organizações da sociedade civil no processo de formulação de políticas públicas foi transformado em modelo de gestão pública contemporânea.

As metodologias de operacionalização da participação social assumem formatos diversos, a exemplo das consultas públicas, dos júris de cidadãos, grupos focais, dos exercícios de projeção de cenários, mapeamentos multicritérios, reuniões de construção de consenso, entre outras modalidades (SMITH et al., 2001; TORGERSEN, 2001). Além disso, tais metodologias diferem entre si em relação a dois critérios: (i) grau de participação do público e; (ii) instituição proponente. 
Em relação ao primeiro critério, os procedimentos empregados variam em um continuum pontuado por três estágios: informação; consulta e negociação. A efetivação de um estágio não conduz, necessariamente, à implantação do próximo e os exercícios de participação social não precisam contemplar as três fases para que se caracterizem como metodologias participativas (SCOONES, 2003). Para Young (2001), a escolha da(s) metodologia(s) associa-se à identificação do grau de participação que se almeja alcançar e também do arranjo mais factível, diante de possíveis limitações trazidas pelo contexto (abrangência do tema, distância física, pulverização do público, ausência de representação organizada etc.)

No primeiro estágio do continuum, o objetivo é influenciar a formação da opinião pública através da intensificação dos procedimentos de informação e/ou construir relações mais transparentes entre as instâncias decisórias e os cidadãos mediante a prestação de contas. No segundo estágio, os cidadãos são convocados a emitir sua opinião a respeito de determinado tema (através de consultas públicas, júris de cidadãos, surveys, grupos focais), sem que exista, necessariamente, o compromisso com a incorporação destes resultados à decisão política final. No terceiro estágio, a participação estende-se até a etapa da negociação e da deliberação sobre a forma final de uma lei, um plano, um dispositivo.

Quanto à origem da instituição proponente, observa-se que a participação social pode ser promovida e facilitada por diferentes organizações, além daquelas pertencentes à esfera governamental. Isto é, mecanismos de consulta, 
participação e informação podem ser "formais" ou "informais", apresentando-se tanto sob a forma top-down quanto bottom-up (IDS, 2003). Diz-se que os arranjos de participação são formais ou top-down quando seguem a lógica convencional de formulação de políticas públicas e são propostos pelas próprias instâncias governamentais. Por outro lado, muitas destas iniciativas emergem "das bases" (bottom-up), tendo como instituições proponentes organizações da sociedade civil. Cada uma destas modalidades tem suas forças e fraquezas e exerce diferentes papéis. Isto significa que os governos não precisam, necessariamente, exercer o papel de instituição proponente em todos os exercícios de participação pública. Mas podem contribuir fortemente para a construção das condições institucionais que encorajem e possibilitem o engajamento e atuação de outros atores sociais no processo (CEFIC, 1997).

Ainda que a participação social já tenha apresentado resultados tangíveis em alguns países, no que diz respeito a modelos e arranjos institucionais de participação pública, não se pode falar na existência de "melhores práticas", metodologias universais ou soluções genéricas, prontamente replicáveis. Aliás, se há alguma consideração-chave a ser feita quando se trata da participação do público na construção de políticas, ou em qualquer outro domínio, é que o contexto local (social, político, econômico, cultural) realmente importa e faz diferença. Resultados bem sucedidos devem ser interpretados à luz da cultura política local e da tradição institucional que permitiu aos governos e à sociedade civil destes países extrair ganhos e benefícios destes exercícios. 
Com a popularização da internet, desenvolvem-se novas formas de decisão política. As consultas públicas on-line são uma delas, apontadas como possíveis canais institucionais de ampliação da participação da sociedade na formulação de políticas públicas. Desde 2003, os websites do governo federal brasileiro já estão explorando as novas tecnologias nesse sentido, especialmente para consultar setores estratégicos para a definição de políticas de saúde e meio-ambiente.

A participação efetiva em consultas públicas apresenta algumas singularidades: requer conhecimentos e informações que sustentem a formação de perspectivas e sugestões consistentes. Setores governamentais submetem uma versão inicial do texto sob consulta pela internet, e indivíduos e setores se manifestam sobre os aspectos propostos, indicam a necessidade de mudanças, justificam o porquê das sugestões, conhecem as contribuições de outros participantes, reveem seus conceitos após descobrir as posições alheias e combinam-se com outros para juntos propor alterações. A participação, portanto, deve ser sustentada por conhecimentos abrangentes, a fim de que a contribuição seja relevante. Os meios de comunicação, neste contexto, revelam-se em sua importância para a formação dos cidadãos e o esclarecimento de setores sociais através da divulgação de informações sobre as mais variadas temáticas.

Há autores que vislumbram nos mecanismos de consulta pública on-line uma possível contribuição para reverter o processo de erosão da legitimidade do processo democrático, ao permitirem que a sociedade se expresse em novos canais sobre a formulação de políticas públicas. Nesse sentido, elas se apresentariam como ferramentas a 
serviço da "democracia digital", capaz de minimizar uma suposta crise existente nas práticas democráticas e formas institucionais de representação política. Adicionalmente, há autores que associam a participação em consultas públicas ao fortalecimento do capital social de redes de atores e grupos de interesse: consultas públicas on-line estudadas por Coleman (2004) indicam que as redes sociais construídas exclusivamente por ocasião de uma consulta podem perdurar mesmo após o fim do período de recebimento de contribuições, com posterior troca de experiências, informações etc. $\mathrm{O}$ fortalecimento de setores sociais e suas reivindicações seriam, assim, um resultado que extrapola o horizonte de uso do meio digital em si, e pode ser antecipado pelos planejadores de consultas como um de seus objetivos. Isso porque a participação social teria, nesse caso, o sentido de apelo e convocação dos cidadãos e das organizações da sociedade civil para compartilhar a decisão em matéria de políticas públicas.

Admite-se que criação de canais institucionais como consultas públicas on-line significa um avanço promissor, mas com resultados que, de fato, ainda não foram estudados devidamente. Diante do potencial das novas tecnologias para o aprofundamento da democracia, surge a demanda por conhecimento sobre as virtudes e as insuficiências das consultas on-line já realizadas, em andamento e futuras no âmbito dos websites do governo federal brasileiro. Para tal, cabe verificar a qualidade da informação on-line oferecida pelas muitas instâncias governamentais e avaliar se esse suporte tecnológico é adequadamente explorado a fim de subsidiar a inserção eficaz dos setores consultados nos processos de agenda e definição de políticas públicas. 
Isto posto, este trabalho tem por objetivo analisar o uso do conhecimento científico certificado, expresso na forma de citações e referências presentes nos documentos disponibilizados em consultas públicas, como recurso de sustentação de argumentos e estratégia de legitimação de perspectivas dos participantes destas mesmas consultas: tanto seus proponentes (agências governamentais), quanto seus respondentes (sociedade civil, de forma geral). Para tal, foi concebido e empregado um desenho de pesquisa que articula duas abordagens metodológicas: a análise bibliométrica e a análise de enquadramento (framing). $\mathrm{O}$ estudo bibliométrico permitiu a identificação da frequência, distribuição e classificação das fontes citadas, assim como sinalizou áreas de maior interesse para as agências governamentais, cidadãos, grupos sociais e outras instituições participantes. Por sua vez, a análise de enquadramento proporcionou a contextualização das referidas fontes e/ou citações presentes nas consultas avaliadas.

O trabalho é composto de quatro seções e estrutura-se como se segue: na seção 2, apresenta-se o detalhamento dos conceitos teóricos e metodológicos que orientaram a análise das consultas selecionadas; na seção 3, são apresentados e discutidos os resultados desta avaliação; finalmente, na seção 4, são expostas as considerações finais sobre o tema. 


\section{Orientações Teórico-Metodológicas}

Conforme anteriormente referido, a análise das informações disponibilizadas pelas consultas públicas on-line que compõem a amostra de investigação foi feita mediante a combinação de dois métodos distintos, porém complementares: a análise de enquadramento e; o estudo bibliométrico.

Um enquadramento é constituído quando as informações são selecionadas, enfatizadas ou omitidas. Desta seleção, ênfase ou exclusão, resulta a apresentação de uma gama de perspectivas gerais, que favorece a percepção de fatos e situações de acordo com um ponto de vista, em detrimento de outros. Trata-se de uma ideia central que organiza a realidade dentro de determinados eixos de avaliação e apreensão, incluindo o uso de expressões, estruturas de sintaxe, estereótipos, padrões de reconhecimento, etc. Enquadramentos são marcos interpretativos mais gerais, construídos socialmente, que permitem às pessoas fazer sentido dos eventos e das situações sociais.

Para Entman (1993), enquadramentos constituem propriedades específicas da narrativa, as quais encorajam percepções e pensamentos sobre eventos e compreensões particulares. Os enquadramentos podem ser constituídos por palavras, metáforas, expressões, ironias, imagens visuais, insinuações e sugestões:

Enquadrar é selecionar alguns aspectos de uma realidade percebida e torná-los mais salientes num texto comunicativo, de modo a promover uma definição de pro- 
blema particular, uma interpretação causal, avaliação moral e ou recomendação de tratamento (ENTMAN, 1993).

Também é possível compreender como enquadramento o formato escolhido para determinada transmissão de mensagem. É o recorte efetuado na transmissão de uma mensagem de acordo com os entendimentos do seu idealizador. Assim, o enquadramento proporciona interpretações dos fatos, sem que a opinião do emissor da mensagem esteja necessariamente explícita.

Estudos recentes têm relacionado os enquadramentos às percepções da audiência sobre os assuntos reportados, demonstrando que eles podem ter consequências sobre a forma como estas audiências percebem e compreendem um assunto ou evento, podendo até mesmo alterar suas opiniões (SHEN; EDWARDS, 2005). Estes estudos concluem que os "efeitos de enquadramento" ocorrem porque as pessoas têm a tendência para empregar "atalhos cognitivos" ou heurísticos para processar a informação, baseando-se nas informações disponíveis para fazerem seus julgamentos.

Nesse sentido, pode-se dizer que enquadramentos também representam matrizes cognitivas. Este último conceito emergiu de investigações no campo da psicologia experimental, realizadas com o intuito de desvendar como os indivíduos organizam sua experiência diária, envolvendo as dimensões racionais, afetivas e emocionais e de comportamento (KAHNEMAN; TVERSKY, 1984; GOFFMAN, 1986; GROSS; D'AMBROSIO, 2004; DRUCKMAN; NELSON, 2003; NELSON; OXLEY, 1999; CHONG; DRUCKMAN, 2007).

A aplicação de métodos bibliométricos, por sua vez, permitiu aos autores a análise das citações de trabalhos 
científicos presentes nos textos das consultas públicas. Observou-se que o emprego de citações é um recurso frequente nas consultas públicas on-line disponibilizadas nos websites governamentais brasileiros. A utilização do conhecimento científico certificado como instrumento de legitimação de perspectivas é sustentada tanto pelo governo brasileiro (proponente das consultas on-line) quanto pelos participantes destas consultas (em seus comentários). Esta constatação confirma os argumentos de Nowotny (2007), para quem o conhecimento científico certificado é um poderoso recurso político.

Consequentemente, a citação do conhecimento científico certificado em textos de consultas públicas pode ser vista como um recurso com duas implicações distintas. Do ponto de vista normativo da teoria democrática, considera-se que se a democracia digital deve tornar a deliberação acessível a qualquer um. Nesse sentido, referências científicas em um documento submetido à consulta podem ampliar substantivamente a compreensão da proposta. Mas também podem criar empecilhos à participação do público não expert, caso as referências sejam apresentadas em termos esotéricos e desprovidas de explicação/contextualização/ exemplificação.

Tendo em vista esta dupla implicação, neste trabalho, analisa-se o contexto das citações empregadas nos textos das consultas públicas on-line. A citação está desassociada de explicações e argumentos substantivos ou foi apresentada de forma acessível e esclarecedora? As referências ao conhecimento científico certificado contribuíram para um melhor entendimento do texto ou criaram novos obstáculos 
à sua interpretação, por parte do público dito "leigo"? As técnicas bibliométricas e cientométricas (AHMED et al., 2004; BRAMBILLAet al., 2006; PAUL, 2000; LEYDESDORFF, 2001), associadas à análise de enquadramento, permitiram aos autores responder a estas questões.

A metodologia está baseada no estudo bibliométrico e de enquadramento para a verificação do ranking, frequência e distribuição das fontes citadas e para a identificação de áreas de interesse das instituições governamentais, cidadãos e grupos sociais. Com este intuito, foram construídas três categorias para a identificação dos propósitos da citação ou do uso do conhecimento científico certificado:

a) sustentar um argumento: a citação é feita de tal forma que o conteúdo original é apresentado de forma inteligível, geralmente com citações diretas ou indiretas, com referências claras ao pensamento do autor. O efeito provável é que o leitor sinta-se encorajado a participar da consulta, ou por sentir-se "bem informado" ou por entender que o proponente da referida consulta (o governo) adota uma postura responsável, ao explicar os significados de um projeto ou de proposta de política pública;

b) valorizar um ponto de vista: a citação é feita exclusivamente com o propósito de dar credibilidade a um argumento, não fazendo diferença para a compreensão do mesmo;

c) evitar explicações: a citação é feita sem os esclarecimentos necessários, de maneira que sua presença tende a dificultar, ao invés de esclarecer, a compreensão do argumento relacionado. 
A amostra analisada compreendeu oito consultas públicas on-line, ocorridas entre 2003 e 2008, que subsidiaram a formulação das seguintes políticas públicas de saúde:

1) Política Nacional de Saúde do Homem (contribuições recebidas entre 10 e 30 setembro 2008);

2) Política Nacional de Saúde de Gays, Lésbicas, Bissexuais e Transgêneros (contribuições recebidas entre 20 e 30 julho de 2008);

3) Política Nacional de Gestão de Tecnologias em Saúde (16 de outubro a 16 de novembro de 2006)

4) Parâmetros para registro médico de idosos, de acordo com a Política Nacional de Idosos (12 julho - 12 agosto de 2005);

5) Política Nacional de Saúde dos Jovens e Adolescentes (16 junho - 16 julho de 2005);

6) Política Nacional de Segurança e Saúde Ocupacional (5 de maio - 30 de novembro de 2005);

7) Agenda Nacional de Prioridades de Pesquisa em Saúde (23 março - 8 maio de 2004);

8) Política Nacional de Informaçãoe Informática doSistema Único de Saúde (27 de novembro - 15 de dezembro de 2003).

Após as contribuições, três versões das políticas anteriormente referidas foram publicadas pelo governo brasileiro:

1) Política Nacional de Gestão de Tecnologias em Saúde;

2) Agenda Nacional de Prioridades de Pesquisa em Saúde; 
3) Política Nacional de Informação e Informática do Sistema Único de Saúde.

Portanto, a amostra investigada compreendeu 11 unidades de análise. Estas foram selecionadas porque, dentre as propostas de políticas de saúde postas sob consulta - e em cujos documentos foram empregadas citações de trabalhos científicos - são as mais representativas em termos de impacto sobre as previsões orçamentárias do Ministério da Saúde, no período de 2003 a 2008.

A política de saúde é "parte integrante do ambiente sócio-político dos povos e, como tal, um fator importante na prevenção e promoção da saúde, à medida que pode operar como um potencializador de comportamentos de saúde" (VON LENGERKE et al., 2004, p.158). Por esta razão, deve ser levada em consideração, juntamente com outras áreas de políticas públicas. "Em muitas partes do mundo, há um crescente compromisso com a ideia de que as políticas e intervenções públicas em todos os domínios (não só no setor médico) devem ser analisadas em termos do seu impacto potencial na saúde pública", de acordo com Curtis (2008, p.293). Isso pode ser visto como parte de uma estratégia mais ampla de promoção de políticas públicas sustentáveis e socialmente responsáveis, adotando uma perspectiva que considera fatores sociais e ambientais como determinantes do estado de saúde pública (CURTIS, op.cit., p.293).

Em síntese, a política de saúde relaciona-se com fatores que transcendem o universo da atenção à saúde, posto que seus resultados dependem também de determinantes sociais, econômicos e políticos. Assim como qualquer outro processo decisório, a política de saúde é fruto de um 
complexo jogo de negociações e confrontações entre a burocracia estatal, profissionais de saúde, sindicatos, partidos políticos, grupos de interesse e associações da sociedade civil. Logo, no setor da saúde, como nos outros espaços do processo de decisão política, os grupos se organizam e negociam seus interesses.

As soluções tecnológicas representadas pelos sistemas de informação das consultas públicas on-line constituem um novo espaço de deliberação em torno de políticas de saúde. Cumpre ressaltar que as consultas públicas on-line integrantes da amostra não foram avaliadas do ponto de vista de seus protocolos técnicos. Os dados brutos de citações e listas de referências foram tratados com o software "Vantage Point 5".

\section{Apresentação e Discussão dos resultados}

A análise da amostra identificou 278 citações de trabalhos científicos publicados entre 1948 e 2008. No que diz respeito à distribuição das citações, verificou-se que $46 \%$ constavam nas versões preliminares de políticas públicas compiladas pelas agências governamentais após a realização das consultas, enquanto as demais $54 \%$ foram encontradas nos comentários dos participantes e nas instruções para as consultas disponibilizadas pelas agências governamentais proponentes.

A maior parte das citações (60\% da amostra ou 167 citações) corresponde a trabalhos publicados nos últimos dez anos (2000 a 2008). Citações de trabalhos publicados na década de 90 representaram 29\% da amostra (80 citações). 
Para citações de trabalhos publicados nos anos 80 e 70, ou mesmo em anos anteriores, as porcentagens encontradas foram 6\% (16 citações) e 5\% (11 citações), respectivamente (Figura 1). Estes dados induzem a conclusão de que o critério de novidade, ou, pelo menos, de contemporaneidade do trabalho científico, é associado à maior capacidade de conferir legitimidade e/ou influência a um argumento mobilizado nos debates on-line.

Figura 1. Distribuição das citações ao longo do tempo.

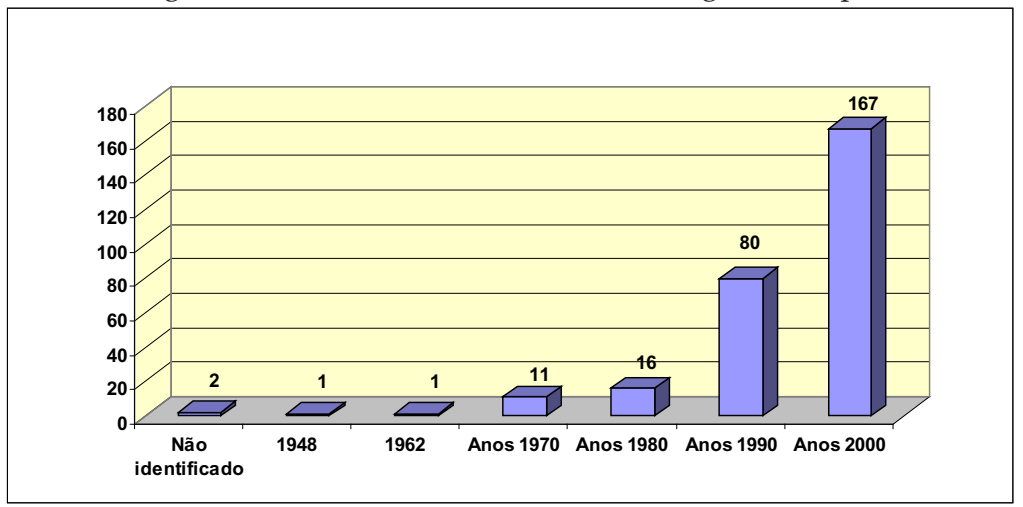

O número total de autores citados correspondeu a 313, distribuídos entre pesquisadores (222) e instituições (91). Estas últimas se referiam a agências governamentais brasileiras (tais como o Instituto Brasileiro de Geografia e Estatística - IBGE e o Ministério da Saúde), estrangeiras (Office of Technology Assessment - OTA ${ }^{1}$ e National

1 Órgão de assessoramento do governo dos EUA, que funcionou entre 1972 e 1995. Sua missão era providenciar estudos prospectivos e ou avaliações de riscos relacionados a problemas considerados de grande 
Health System²), organismos multilaterais (Organização Mundial de Saúde - OMS, Organização Pan-americana de Saúde, UNESCO³, Organização para a Cooperação e Desenvolvimento Econômico - OCDE) e associações médicas profissionais.

Os números obtidos revelam que, ao menos no universo das consultas públicas on-line na área de saúde, instituições governamentais de renome foram suplantadas pelos pesquisadores acadêmicos como fonte de informações supostamente confiáveis. A preponderância de citações de trabalhos acadêmicos em detrimento das citações institucionais é um dado curioso, uma vez que contraria o senso comum de que as informações produzidas e publicadas por organizações oficiais constituem uma referência primordial no debate de políticas públicas. Os resultados desta análise demonstram a preferência por outras fontes de informação, ao mesmo tempo em que sugerem um impacto nada desprezível dos resultados das pesquisas acadêmicas no debate que fomenta as consultas públicas na área de saúde, no Brasil.

Cumpre ressaltar, no entanto, que os dados encontrados apenas evidenciam a influência dos resultados da pesquisa acadêmica no debate que antecede a formulação das políticas, em meio virtual. Porém, eles nada dizem (nem foi esta a intenção dos autores) sobre a incorporação destes mesmos resultados no processo de institucionalização

complexidade científica ou tecnológica. Foi um dos organismos pioneiros na divulgação por meio eletrônico de documentos e relatórios considerados de interesse público

2 Sistema Nacional de Saúde do Reino Unido.

3 Organização das Nações Unidas para Educação, Ciências e Cultura. 
das políticas públicas, após as consultas on-line. Para tal, é preciso o emprego de outras metodologias combinadas à análise de conteúdo e à cientometria .

Autores

Número de

\begin{tabular}{lc} 
& citações \\
\hline Brasil (leis e quadro regulatório) & 35 \\
\hline Campbell, L.M. & 6 \\
Hunter, C. & 6 \\
\hline Morris, L. & 6 \\
Taylor, M.W. & 6 \\
\hline Schraiber, L.B. & 5 \\
Gomes, R. & 4 \\
\hline Moraes, I.H.S. & 4 \\
Ministério da Saúde & 4 \\
\hline National Health System - NHS (Reino Unido) & 4 \\
Organização Pan-americana de Saúde & 4 \\
\hline Office of Technology Assessment - OTA (EUA) & 4 \\
Outros & 399 \\
\hline Total & 487 \\
\hline
\end{tabular}

Tabela 1. Número de citações/autores.

Ainda no que diz respeito à natureza da autoria (Tabela 1), a análise das citações gerou outras conclusões relevantes e surpreendentes, além das anteriormente citadas. Na amostra, trabalhos de autoria individual foram os mais frequentemente citados: 189 entre 278 (68\% da amostra) contra

4 É intenção dos autores dar desdobramento aos resultados desta pesquisa, em um segundo momento, incorporando novas metodologias e explorando os aspectos de expertise e formulação de políticas públicas, aqui sugeridos. 
89 trabalhos (32\%) publicados em coautoria. É sabido que a pesquisa na área de saúde - se comparada a outras, como as ciências sociais - usualmente demanda grandes investimentos e a formação de equipes razoavelmente numerosas e, não raro, multidisciplinares. Os resultados publicados por estas equipes são reputados como de alto impacto sobre o avanço do conhecimento científico na área e também sobre a prática médica. Entretanto, tanto as agências governamentais proponentes quanto os participantes das consultas on-line recorreram, com mais frequência, à citação de trabalhos individuais (cujos resultados são, supostamente, menos representativos) para fundamentar seus argumentos e sustentar seus pontos de vista.

Quanto à origem das citações da amostra, a análise identificou a ocorrência de 12 tipos ou categorias diferentes (vide Figura 2): artigos publicados em periódicos (92); livros (68); documentos oficiais (33); legislação (32); capítulos de livros (26); teses e dissertações (9); websites (5); white papers (2), estatísticas (1); relatórios (1) e outros, tais como artigos publicados por organizações não-governamentais (9). Livros, capítulos de livros e artigos de periódicos constituíram, portanto, 67\% (186 citações) da amostra, enquanto todas as demais categorias somadas corresponderam a 33\% (92 citações). Mais uma vez, os resultados corroboram a observação de que os meios convencionais de comunicação acadêmica e de publicação do dito conhecimento científico certificado foram privilegiados em detrimento de outras fontes, inclusive as governamentais. 
Figura 2. Distribuição dos documentos, por tipos ou categorias.

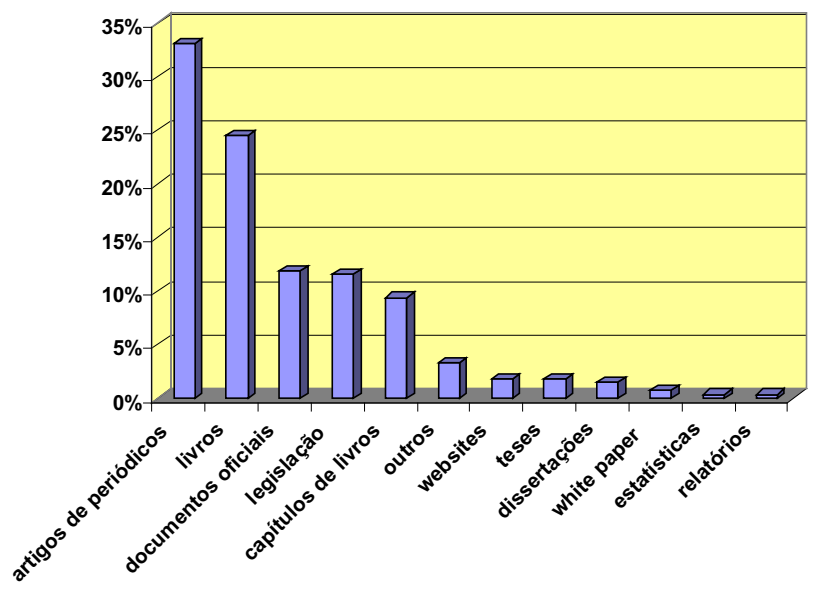

Os 92 artigos citados foram publicados em 43 periódicos científicos, dos quais apenas 14 (o equivalente a 32,6\% do total) são publicados no Brasil (vide Figura 3).

Figura 3. Distribuição dos artigos por periódicos (Brasil)

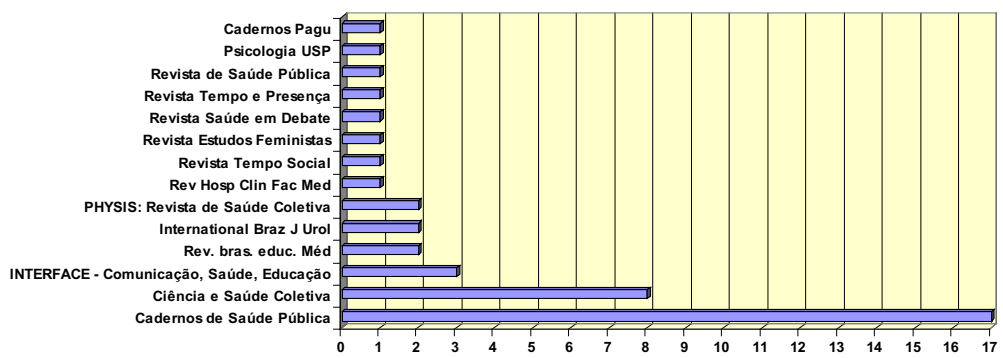


Os outros 29 periódicos são publicados na Europa e nas Américas (com exceção do Brasil). O inglês é o idioma de publicação predominante destes periódicos (27 ou $62,8 \%$ do total), seguido pelo Português (13 periódicos ou 30,2\%), Espanhol (2 ou 4,7\%) e Alemão (1 ou 2,3\%). A partir destes dados, conclui-se que a compreensão do idioma inglês parece condição indispensável para aqueles que desejam sustentar seus argumentos a partir da referência ao conhecimento científico certificado na área de saúde. Tendo em vista o peso atribuído pelos participantes das consultas públicas analisadas a esta forma de conhecimento, pode-se dizer que apenas o domínio do idioma natal não garante aos participantes a possibilidade de consultar as fontes, aprofundar o entendimento e, eventualmente, contestar com propriedade muitos dos conceitos relevantes utilizados nas consultas públicas on-line no Brasil, na área de saúde.

\begin{tabular}{|l|c|}
\hline Periódicos & $\begin{array}{c}\text { Número de } \\
\text { artigos }\end{array}$ \\
\hline International Journal of Medical Informatics & 6 \\
\hline Informatics in Primary Care & 6 \\
\hline Child and Adolescent Psychiatric Clinics of North America & 3 \\
\hline Health Policy & 3 \\
\hline Revista Cubana de Educación Médica & 3 \\
\hline Atencion Primaria & 2 \\
\hline The New England Journal of Medicine & 2 \\
\hline JAMA & 2 \\
\hline Administrative Science Quarterly & 2 \\
\hline International Journal of Health Services & 2 \\
\hline Annals of Internal Medicine & 1 \\
\hline Journal of Urology & 1 \\
\hline
\end{tabular}




\begin{tabular}{|l|c|}
\hline Periódicos & $\begin{array}{c}\text { Número de } \\
\text { artigos }\end{array}$ \\
\hline Journal of Pediatric Oncology Nursing & 1 \\
\hline Journal of Health Politic, Policy and Law & 1 \\
\hline Journal of Canadian Medical Association & 1 \\
\hline Journal of Adolescent Health & 1 \\
\hline BMJ & 1 \\
\hline Journal of Clinical Endocrinology and Metabolism & 1 \\
\hline AIDS Patient Care and STDs & 1 \\
\hline Canadian Journal of Cardiology & 1 \\
\hline International Journal of Epidemiology & 1 \\
\hline The Policy Journal of the Health Sphere & 1 \\
\hline Urology (Ridgewood) & 1 \\
\hline Bulletin von Medicus Mundi Schweiz & 1 \\
\hline La Clinica Terapeutica & 1 \\
\hline Texas Medicine & 1 \\
\hline Social Science and Medicine & 1 \\
\hline International Journal of Technology & 1 \\
\hline Assessment in Health Care & 1 \\
\hline Revista Pan-americana de Salud Publica & $\mathbf{5 0}$ \\
\hline Total & \\
\hline
\end{tabular}

Quadro 2. Distribuição dos artigos (outros países).

Na análise da amostra, verificou-se a ocorrência de 196 citações empregadas pelas agências governamentais, seja em documentos que apresentam os objetivos e a mecânica das consultas públicas disponibilizadas on-line, seja em versões preliminares de políticas públicas disponibilizadas nos sites oficiais após a realização das consultas. Dentre as razões do emprego da citação pelas agências governamentais, a categoria " $b$ "- valorização de um ponto de vista - foi verificada em 111 (46,2\%) das citações, seguida da categoria 
"c" - evitar explicações (100 ou 41,7\%) e da categoria "a" sustentar um argumento (29 ou 12,1\%). Nos comentários publicados pelos participantes/respondentes das consultas, identificou-se a categoria " $c$ " (24 ou 55\%) como a principal razão da citação, seguida da categoria " $b$ " (15 ou 34\%) e da categoria "a" (5 ou 11\%).

Figura 4. Razões da citação pelas agências governamentais.

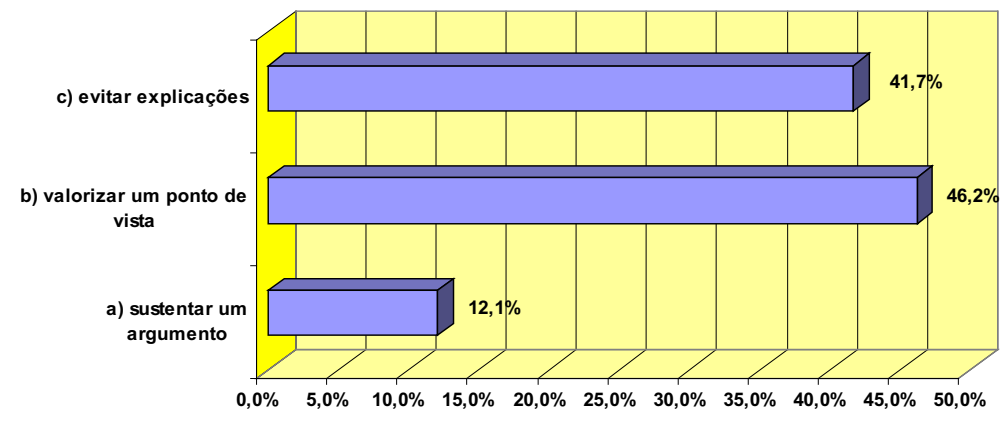

\section{Conclusões}

O tema de pesquisa aqui apresentado propõe uma trilha de investigação que ainda não foi explorada apropriadamente e em todas as suas possibilidades. Neste trabalho, combinou-se a análise de conteúdo à cientometria aplicada, tendo em vista a produção de dados que ampliasse a compreensão de como o conhecimento científico certificado é utilizado nas consultas públicas on-line realizadas no Brasil. Por extensão, podem-se tecer inferências sobre a natureza e os impactos da contribuição desta forma de 
conhecimento para a ampliação dos canais de participação social na formulação de políticas públicas.

Em linhas gerais, e com base nos dados anteriormente expostos, pode-se dizer que tanto as agências governamentais quanto os participantes das consultas analisadas privilegiaram: (a) trabalhos científicos recentemente publicados, sobretudo entre 2000 e 2008; (b) fontes acadêmicas, ao invés de documentos oficiais; (c) periódicos científicos publicados na Europa e nas Américas (com exceção do Brasil), a maior parte em língua inglesa. Adicionalmente, concluímos que as referências a trabalhos científicos, apenas em raras ocasiões, foram feitas com o objetivo de esclarecer ou ampliar a compreensão de um tópico em discussão. Na maior parte dos casos, as citações foram empregadas como recurso de valorização ou reforço da suposta credibilidade de um argumento (quando mencionadas pelas agências governamentais) ou como forma de evitar explicações mais profundas, necessárias para a correta apreensão de uma perspectiva ou ponto de vista (quando empregadas pelos participantes/respondentes das consultas).

Agradecimentos: ao Ministério da Educação e sua agência de fomento CAPES (Coordenação de Aperfeiçoamento de Pessoal de Nível Superior) por apoiar esta pesquisa através do programa PRODOC. 


\section{Referências}

AHMED, T., et al. Highly cited old papers and the reasons why they continue to be cited. Part II. The 1953 Watson and Crick article on the structure of DNA. Scientometrics, v.61, n.2, p.147-156. 2004.

BRAMBILLA, S. D. S., VANZ, S. A. S.; STUMPF, I. R. C. Mapeamento de um artigo produzido na UFRGS: razões das citações recebidas. Enc. Bibli: R. Eletr. Bibliotecon. Ci. Inf., Florianópolis, n.esp, 1ํo sem., p.195-208. 2006.

CHONG, D.; DRUCKMAN, J. N. A theory of framing and opinion formation in competitive elite environments. Journal of Communication, v.57, n.1, p.99-118, 2007

COLEMAN, S. Connecting parliament to the public via the internet: Two case studies of online consultations. Information, Communication and Society, v.7, n.1, p.1-22, 2004.

CURTIS, S. How can we address health inequality through healthy public policy in Europe? European Urban and Regional Studies, v.15, n.4, p.293-305, 2008.

DRUCKMAN, J. N.; NELSON, K. R. Framing and deliberation: How citizens' conversations limit elite influence. American Journal of Political Science, v.47, n.4, p.729745, 2003. 
ENTMAN, R. M. Framing: Toward Clarification of a Fractured Paradigm. Journal of Communication, v.43, n.4, p.51-8, 1993.

GAMSON, W. A.; MODIGLIANI, A. Media discourse and public opinion on nuclear power: A constructionist approach. The American Journal of Sociology, v.95, n.1, p.1-37, 1989.

GOFFMAN, E. Frame analysis. Boston: Northeastern University Press.

GROSS, K.; D'AMBROSIO, L. Framing emotional response. Political Psychology, v.25, n.1, p.1-29, 1986.

KAHNEMAN, D.; TVERSKY, A. Choices, values, and frames. American Psychologist, v.39, n.4, p.341-350, 1984.

LEYDESDORFF, L. The challenge of Scientometrics: The development, measurement, and self-organization of scientific communications. Boca Raton, FL: UniversalPublishers. 2001.

NELSON, T. E.; OXLEY, Z. M. Issue framing effects on belief importance and opinion. The Journal of Politics, v.61, n.4, p.1040-1067, 1999.

NOWOTNY, H. Transgressive competence: The narrative of expertise. European Journal of Social Theory, v.3, n.1, p.5-21, 2000. 
PAUL, D. In citing chaos: A study of the rhetorical use of citations. Journal of Business and Technical Communication, v.14, n.2, p.185-222, 2000.

SHEN, F.; EDWARDS, H. H. Economic Individualism, Humanitarianism, and Welfare Reform: A Value-Based Account of Framing Effects. Journal of Communication, v.55, n.4, p.795-809, 2005.

VON LENGERKE, T. Perception and health behaviours: A multilevel analysis and implications for public health psychology. Journal of Health Psychology, v.9, n.1, p.157175, 2004.

WRIGHT, S.; STREET, J. Democracy, deliberation and design: The case of online discussion forums. New Media and Society, v.9, n.5, p.849-869, 2007. 
